\title{
Properties that influence business process management maturity and its effect on organizational performance
}

\author{
Remco Dijkman ${ }^{1}$ - Sander Vincent Lammers ${ }^{1}$ - Ad de Jong ${ }^{2}$
}

Published online: 28 April 2015

(C) The Author(s) 2015. This article is published with open access at Springerlink.com

\begin{abstract}
BPM maturity is a measure to evaluate how professionally an organization manages its business processes. Previous research provides evidence that higher BPM maturity leads to better performance of processes and of the organization as a whole. It also claims that different organizations should strive for different levels of maturity, depending on their properties. This paper presents an empirical investigation of these claims, based on a sample of 120 organizations and looking at a selection of organizational properties. Our results reveal that higher BPM maturity contributes to better performance, but only up to a point. Interestingly, it contradicts the popular belief that higher innovativeness is associated with lower BPM maturity, rather showing that higher innovativeness is associated with higher BPM maturity. In addition, the paper shows that companies in different regions have a different level of BPM maturity. These findings can be used as a benchmark and a motivation for organizations to increase their BPM maturity.
\end{abstract}

Keywords Business process $\cdot$ Business process management $\cdot$ Maturity $\cdot$ Innovativeness $\cdot$ Performance

Remco Dijkman

r.m.dijkman@tue.nl

1 Eindhoven University of Technology, Den Dolech 2, 5612 AZ, Eindhoven, The Netherlands

2 Aston Business School, Aston Triangle, Birmingham, B4 7ET UK

\section{Introduction}

Business Process Management (BPM) is a contemporary management technique that focuses on managing an organization's operations in terms of 'business processes'. Business processes are structured, measured sets of activities designed to produce a specific output for a particular customer or market (Davenport 1993). BPM delivers the methods, tools and techniques to identify, analyse, execute, monitor and change these business processes, resulting in a cycle of continuous improvement (Davenport 1993). It is often contrasted with the more traditional function-based management, in that emphasizes customers and relations between activities and, by doing so, aims to achieve higher customer satisfaction and better collaboration between individual business functions (Dumas et al. 2013).

When engaging in business process management, organizations will at some stage ask themselves how capable they are in doing so, and to what extent they reap the benefits. Maturity models have emerged as a measure to evaluate the capabilities of an organization in a certain discipline (De Bruin et al. 2005a). They became popular with the Capability Maturity Model (CMM) (Paulk 1993). The CMM and other maturity models operate as a tool that enables organizations to rank specific processes according to how structured they are described, managed, measured and optimized. Processes that have a higher rank - also called a higher level of maturity - are claimed to be associated with better performance of those processes and in particular with better quality output. This claim is supported by a large number of studies (e.g.: Jiang et al. 2004; Herbsleb and Zubrow 1997; Herbsleb and Goldenson 1996; Krishnan and Kellner 1999; Krishnan and Kriebel 2000), an overview 
of which will be presented in Section 3. However, these studies focus on the maturity and performance of a single process or set of processes for performing a particular business function (such as software development or purchasing), while BPM studies show how the entire collection of business processes in the organization is managed in general. There are some studies that provide initial evidence to support the claim that organizations with a higher general BPM maturity perform better as a whole (McCormack 2001; Škrinjar et al. 2008), investigating different aspects of organizational performance, such as financial performance and employee satisfaction. However, these studies were conducted for a maturity-related construct called 'Business Process Orientation' (McCormack et al. 2009), which measures whether an organization works in a process oriented manner, rather than how an organization implements its BPM capability. This motivates our investigation into a more direct relation between BPM maturity and organizational performance. The value of showing this relation lies therein, that it can serve as a means to convince higher management of the use of BPM maturity and as a strong business case for engaging in a project to reach higher levels of BPM maturity. Therefore, the first research question of this paper is:

RQ1 Do high levels of BPM maturity lead to improved organizational performance?

Since BPM maturity is defined on an ordinal scale, the idea easily arises that a higher level of maturity always leads to better performance. However, there is an increasing awareness that, whether a higher level of maturity leads to better performance, may depend on certain properties of that organization (Niehaves et al. 2014); for some organizations the optimal level of maturity may not necessarily be the highest level of maturity. In particular, there is a strong belief among researchers and practitioners that maturity models make organizations rigid and bureaucratic (Adler et al. 2005; Antoniol et al. 2004; Nawrocki et al. 2002) and, therefore, negatively affect innovativeness (Herbsleb and Zubrow 1997). This belief is based on the idea that higher BPM maturity implies more strictly defined processes, which negatively influence an organization's potential for finding creative solutions to technical problems. Therefore, organizations that are more innovative, can be expected to strive for less strictly defined processes and therefore have a lower level of BPM maturity. For these reasons, the second research question of this paper is:

RQ2 Which organizational properties influence the attainment of BPM maturity levels?

To answer the research questions, this paper reports on an empirical investigation into the relation between an organization's innovativeness, BPM maturity level and performance. Company size, age and geographic location are used as additional properties to explain both the maturity level and the performance of the organization. These properties do not represent an exhaustive enumeration of the properties that an organization should take into account when determining its ideal level of BPM maturity, as will also be shown by the analysis of the data further on in the paper. Rather, this paper investigates some of the properties that are commonly considered to determine whether an organization's BPM maturity is properly tuned to its properties. The empirical investigation involves a survey among 120 organizations in different sectors in both Germany and The Netherlands. In answering the research questions, the paper makes an important contribution to understanding the effect of improving the BPM capability and properties that influence the level of BPM maturity that can be achieved or is desirable to achieve for an organization. In particular, it shows that developing the BPM capability pays off, but up to a point. Also, it disproves popular belief that more innovative companies should strive for a lower level of BPM maturity, in fact showing that the opposite is considered to be true in practice.

The rest of this paper is organized as follows. Section 2 presents a more detailed discussion of BPM Maturity, Section 3 the research model, Section 4 the research method and Section 5 the approach to data collection and the analysis. Section 6 discusses the results. Section 7 presents the conclusions, limitations and future work.

\section{BPM maturity}

Maturity models find their origin in the work of Crosby (1979) and Nolan (1973). Since these initial papers the work on maturity models has proliferated. A large number of new maturity models has been developed (34 new maturity models were developed in 2009 and 2010 alone (Wendler 2012)). The similarities and differences between maturity models are well studied in a number of surveys, that compare various aspects of the maturity models, including aspects of the models themselves (Wangenheim et al. 2010; Mettler et al. 2010) and the research methods that lead to their development (Van Looy et al. 2013; Wendler 2012; De Bruin and Rosemann 2005b; Becker et al. 2009). These surveys show that, while maturity models may differ along a large number of dimensions, the properties that they share and that identify them as maturity models, are that they present a number of stages of maturity and a set of capabilities that can be measured to determine the stage of maturity (Wendler 2012).

With respect to the capabilities that are evaluated by the maturity models, two types of models can be distinguished (De Bruin and Rosemann 2010). First, there are maturity models that evaluate a particular business process or set 
of business processes. Second, there are maturity models that evaluate the capability of an organization to manage their business processes in general. In the first category, there exist maturity models for widely varying business processes, including processes for software development (Paulk 1993), acquisition (Software Engineering Institute 2010a), service delivery (Software Engineering Institute 2010b), software product lines (Ahmed and Capretz 2011), e-government (Andersen and Henriksen 2006), project management (Ibbs and Kwak 2000), and procurement (Batenburg and Versendaal 2008). The focus of this paper is on the second category of maturity models, which are also called Business Process Management (BPM) maturity models. There are notably fewer of these models and even fewer are being applied in practice (Rohloff 2009), exceptions are the BPM maturity models proposed by the OMG (Object Management Group 2008), De Bruin et al. (2005a, 2005b), Rohloff (2009), and Hammer (2007). The difference between measuring the maturity of a single process and measuring the maturity of the Business Process Management capability of an organization is subtle, but leads to widely different measurement models. Maturity models that focus on a particular business process, include indicators that are specific to 'mature' ways of performing that process. For example, the CMMI maturity model for software development (Paulk 1993), has indicators as to whether requirements engineering and testing are done in a structured manner. In contrast, BPM maturity has indicators that are not specific to a particular process. Instead, BPM maturity has indicators that can apply to any process, such as whether the process is documented or whether performance criteria are identified for the process. In addition, BPM maturity models are more likely to apply to the management of multiple different processes at the same time. For example, there may be an indicator to assess whether the company has a process management department that takes care of documenting the processes in the company.
This paper takes the Business Process Maturity Model (BPMM) proposed by the OMG (Object Management Group 2008) as a starting point, because it is defined as an international standard. BPMM distinguishes five maturity levels as illustrated in Fig. 1. The five levels explain an organization how it can gradually improve its BPM capability. For example, to get from level 1 to level 2, repeatable work practices have to be introduced. The BPMM standard specifies in detail which areas of business process management have to be improved to reach a certain level and which specific goals have to be achieved in each of these areas to reach that level. For example, in order to reach level 2, an organization has to work on the process area 'process and product assurance' and one of the specific goals that must be met is that the organization tracks, communicates and resolves non-conformance issues. Specific practices must be implemented to reach the specific goals, such as the specific practice that the results of assurance evaluations are reviewed with responsible parties on a regular basis. For a company to prove that it indeed is at a certain level of maturity, it needs to demonstrate that it has implemented the specific practices. This is normally done by an external organization during an 'appraisal' that involves collecting proof in the form of documents, data and interview transcripts that the company implements the specific practices.

There are a large number of previous studies that show a relation between maturity and some aspect of organization performance. Many of these are case studies (e.g.: Harter et al. 2000; McGarry and Decker 2002; Pitterman 2000; Diaz and Sligo 1997; Diaz and King 2002; Humphrey et al. 1991; Rooijmans et al. 1996; Dion 1992, 1993; Oldham et al. 1999; Urioste 2004; Bowers 2002; Wohlwend and Rosenbaum 1993; Porter and Detoma 1999; Hammer 2007), which report on results that are achieved in single organizations, although about half of them do involve multiple units of analysis (e.g.: multiple projects within the same
Fig. 1 Definition of maturity levels in BPMM

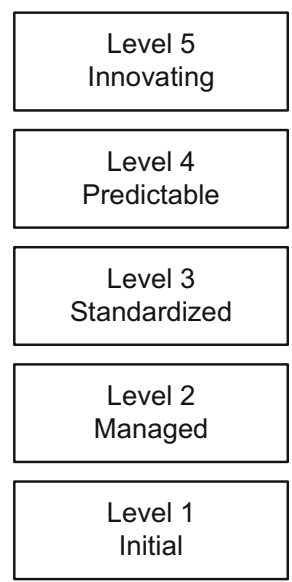

Processes are continuously improved.

Processes are managed quantitatively to establish predictable results.

Standardized processes are established throughout the organization.

Management ensures that work within work-units can be performed in a repeatable manner.

Work is performed in inconsistent and ad-hoc ways. 
organizations). The studies focus on software process maturity, with one exception (Hammer 2007) that studies general BPM maturity. Most of the case studies show a positive relation between the maturity level of a specific group of processes (typically software development processes) and an improvement in the performance and the quality of the output of those processes as well as a reduction in the costs of running them. Additional improvements that are shown by some studies, are an increase in the number of business opportunities, an improved capability to produce an accurate planning as well as improved staff morale, customer satisfaction, control and communication. One study explicitly reported improved overall organizational performance (McGarry and Decker 2002). There are a number of papers that generalize from both case studies in literature and additional case studies, to aggregate overall statistics, such as average return on investment (Gibson et al. 2006; Solingen 2004; Goldenson et al. 1999; Krasner 2001). However, these papers recognize that case studies in particular suffer from a selection bias, as most case studies tend to be success stories (Gibson et al. 2006). In addition to case studies there exists other empirical studies, which show a relation between maturity and organization performance using multiple units of analysis. Table 1 summarizes these studies. For each study, it shows the type of research conducted, the used maturity model and the relations with organization performance that were confirmed by the study. Most of the studies are conducted by means of a survey, but in two cases the study was conducted by investigating data about the cases that was available in some form. Most of the studies focus on CMM or its successor CMMI (CMMI Institute 2011). Three studies investigated the relation between the CMMI maturity level and organizational performance, while three other studies investigated whether the presence of certain CMMI specific practices in an organization affect organizational performance. The other studies introduce their own notions of maturity to investigate the performance of other processes: new product development, supply chain management, purchasing, and order fulfillment. Three of these notions were developed specifically to determine the maturity of the business function that is studied. The others were general maturity notions. Two studies show a relation between the level of 'business process orientation' (which is a concept that is related to and derived from BPM maturity (McCormack et al. 2009)) and overall performance of an organization. Based on this careful inspection of related work, we conclude that little is known today about the effect of engaging in an organization-wide effort to improve the BPM capability. At the same time, generalizing from existing work in specific areas of process maturity, there is ample evidence to support the assumption that improving on the BPM capability in general improves the performance of the organization.

\section{Research model}

The first goal of this paper is to determine whether higher overall BPM maturity level leads to better performance of the organization as a whole (RQ1). The goal of the paper is to study the organization as a whole. Consequently, we look at the performance of the organization as a whole and also the overall maturity level of the processes of the organization. This affects our choice of the way in which the concepts under study are operationalized as well as the people that we target with the survey, as will be explained further on in the paper.

The second goal of this paper is to investigate which organizational properties influence the attainment of BPM maturity (RQ2). While a large number of properties are of interest, we do not aim to give an exhaustive account of the properties that determine the optimal level of BPM maturity of an organization. Rather, we primarily focus on the innovativeness of an organization. Our motivation for that is that the relation between innovativeness and BPM maturity is controversial and can answer an important question for innovative organizations: should our organization strive for higher BPM maturity, or would a higher BPM maturity limit our innovative capability? As additional properties, we study age, size and geographical location of the organization, because they can be considered important descriptive characteristics of an organization (Mintzberg 1979). We acknowledge that there are other properties that influence BPM maturity, such as the type of product and the business model. These properties can be studied in future work.

Against this background, Fig. 2 summarizes the concepts and the relations between these concepts that we aim to study. In the remainder of this section, we discuss these relations based on related work.

Concerning the relation between innovativeness and maturity, one of the most common criticisms of CMMI is that it leads to rigid and bureaucratic organizations (Adler et al. 2005; Antoniol et al. 2004; Nawrocki et al. 2002; Herbsleb and Zubrow 1997), because it imposes strictly defined processes. (Although research has also shown that organizations, in which CMMI was implemented, disagreed with that claim (Herbsleb and Zubrow 1997).) The increased bureaucracy of the organization, can in particular be considered to negatively impact the organization's ability to find creative solutions to technical problems (Herbsleb and Zubrow 1997) and, consequently, hamper the innovative ability of the organization. It has also been argued that each organization should allow for an amount of 'entropy' in its processes that is appropriate for the environment in which it operates. This includes allowing for the 'entropy' that is related to an external pressure to deliver innovative products (Trienekens et al. 2008). These 
Table 1 Empirical studies into the relation between maturity and organizational performance using multiple units of analysis

\begin{tabular}{|c|c|c|c|}
\hline Study & Research method & Maturity model & Confirmed relations \\
\hline Michlmayr (2005) & $\begin{array}{l}\text { Secondary data } \\
\text { (80 units) }\end{array}$ & $\begin{array}{l}\text { Presence of Specific } \\
\text { Quality Practices }\end{array}$ & Open source project success \\
\hline Jiang et al. (2004) & $\begin{array}{l}\text { Survey } \\
\text { (154 respondents) }\end{array}$ & CMM & $\begin{array}{l}\text { Improved learning } \\
\text { Improved control } \\
\text { Improved product quality } \\
\text { and productivity } \\
\text { Improved communication } \\
\text { Improved flexibility }\end{array}$ \\
\hline $\begin{array}{l}\text { Herbsleb and Zubrow (1997), } \\
\text { Herbsleb and Goldenson (1996) }\end{array}$ & $\begin{array}{l}\text { Secondary data } \\
\text { (138 respondents) }\end{array}$ & CMM & $\begin{array}{l}\text { Improved product quality and } \\
\text { productivity } \\
\text { Improved ability to meet } \\
\text { schedule and budget } \\
\text { Improved customer satisfaction } \\
\text { Improved staff morale }\end{array}$ \\
\hline $\begin{array}{l}\text { Krishnan and Kellner (1999), } \\
\text { Krishnan and Kriebel (2000) }\end{array}$ & $\begin{array}{l}\text { Secondary data } \\
\text { (43 units) }\end{array}$ & $\begin{array}{l}\text { Presence of CMM } \\
\text { Specific Practices }\end{array}$ & $\begin{array}{l}\text { Improved product quality and } \\
\text { productivity }\end{array}$ \\
\hline Dooley et al. (2001) & $\begin{array}{l}\text { Survey } \\
\text { (39 respondents) }\end{array}$ & NPD Maturity & $\begin{array}{l}\text { Improved overall performance of the } \\
\text { new product development (NPD) function }\end{array}$ \\
\hline Lockamy III and McCormack (2004) & $\begin{array}{l}\text { Survey } \\
\text { (523 respondents) }\end{array}$ & SCM Maturity & $\begin{array}{l}\text { Improved overall performance of the } \\
\text { supply chain management (SCM) function }\end{array}$ \\
\hline Raschke and Ingraham (2010) & $\begin{array}{l}\text { Survey } \\
\text { ( } 356 \text { respondents) }\end{array}$ & BPMМ & $\begin{array}{l}\text { Improved overall performance of the } \\
\text { purchasing and order fulfillment functions }\end{array}$ \\
\hline Batenburg and Versendaal (2008) & $\begin{array}{l}\text { Survey } \\
\text { (117 respondents) }\end{array}$ & $\begin{array}{l}\text { Purchasing } \\
\text { Maturity }\end{array}$ & $\begin{array}{l}\text { Improved overall performance of the } \\
\text { purchasing function }\end{array}$ \\
\hline Hofmann and Reiner (2006) & $\begin{array}{l}\text { Survey } \\
\text { ( } 60 \text { respondents) }\end{array}$ & Process Maturity & $\begin{array}{l}\text { Improved overall performance of the } \\
\text { supply chain management function }\end{array}$ \\
\hline Škrinjar et al. (2008) & $\begin{array}{l}\text { Survey } \\
\text { (405 respondents) }\end{array}$ & $\begin{array}{l}\text { Business Process } \\
\text { Orientation }\end{array}$ & $\begin{array}{l}\text { Improved overall organizational } \\
\text { performance }\end{array}$ \\
\hline McCormack (2001) & $\begin{array}{l}\text { Survey } \\
\text { (110 respondents) }\end{array}$ & $\begin{array}{l}\text { Business Process } \\
\text { Orientation }\end{array}$ & $\begin{array}{l}\text { Improved overall organizational } \\
\text { performance } \\
\text { Improved staff morale } \\
\text { Improved interdepartmental connectedness } \\
\text { Decreased interdepartmental conflict }\end{array}$ \\
\hline Deephouse et al. (1995) & $\begin{array}{l}\text { Survey } \\
\text { ( } 87 \text { respondents) }\end{array}$ & $\begin{array}{l}\text { Presence of CMM } \\
\text { Specific Practices }\end{array}$ & $\begin{array}{l}\text { Improved product quality } \\
\text { Improved ability to meet schedule and budget } \\
\text { and budget }\end{array}$ \\
\hline Jung and Goldenson (2003) & $\begin{array}{l}\text { Secondary data } \\
\text { (752 units) }\end{array}$ & CMM & $\begin{array}{l}\text { Improved ability to meet schedule and } \\
\text { budget }\end{array}$ \\
\hline Filbeck et al. (2013) & $\begin{array}{l}\text { Secondary data } \\
\text { (348 units) }\end{array}$ & CMM & Improved stock performance \\
\hline
\end{tabular}

findings point towards a possible negative relation between innovativeness and BPM maturity, with more innovative organizations striving for lower levels of BPM maturity. The causality of the relation can also be reversed, because 
Fig. 2 Organization properties, BPM maturity and performance

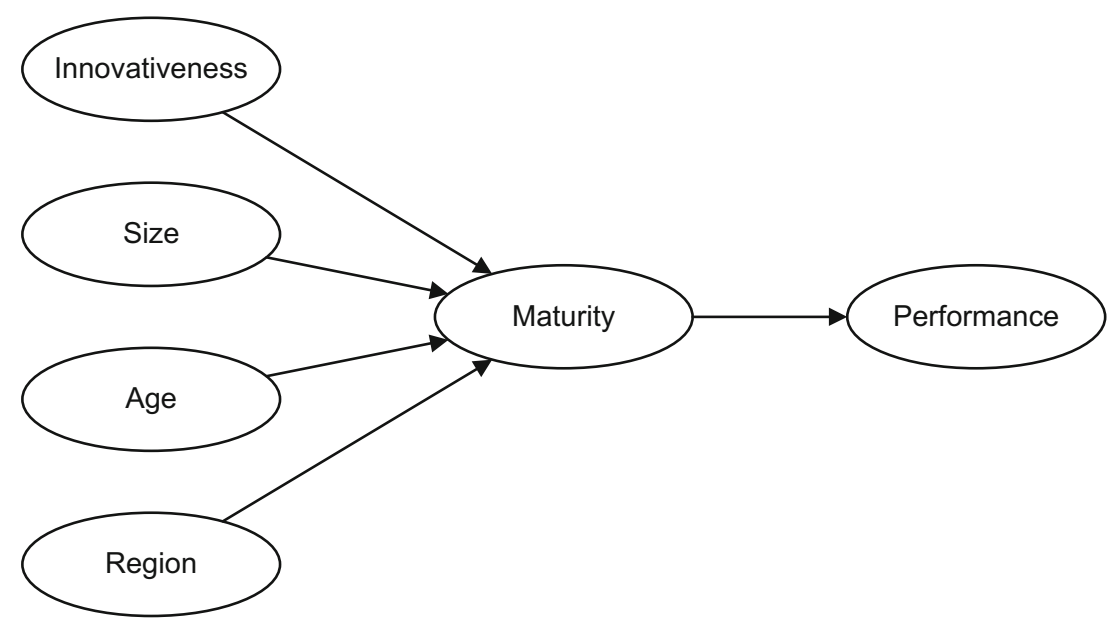

quality management is part of the organization's infrastructure; it facilitates and controls other processes, including innovation processes (for example through the stage gate process (Cooper 1990)). Therefore, quality is a tool that is tuned to the processes that it facilitates and, consequently, causally follows those processes. Indeed in previous research the relation between innovativeness and financial performance has been found to be mediated by quality (Cho and Pucik 2005).

Considering the relation between organizational size and BPM maturity, we argue that larger organizations have more resources to assign to develop a BPM function than smaller organizations. Furthermore, we argue that larger organizations have a more urgent need for better described and more structured processes, because they may otherwise become unmanageable due to their size. We would therefore expect that larger organizations document their business processes more rigorously than smaller equivalents and that larger organizations have more standardized processes across the organization.

Concerning the relation between geographical region and maturity, clearly different geographical regions and in particular different countries have different cultures. This is formalized in the model of cultural dimensions by Hofstede (1980). We expect regional culture to influence the way in which an organization deals with BPM maturity. One particular property of the model of cultural dimensions that is of interest in this context is the uncertainty avoidance index, which quantifies a culture's tolerance for uncertainty and ambiguity. Uncertainty avoiding cultures tend to minimize the possibility of uncertain situations by strict laws and rules, safety and security measures. We argue that organizations in regions that score high on this index, have a higher BPM maturity, because by documenting and formally managing their processes, these organizations can reduce risk and uncertainty. This argument is supported by Humprey, Snyder and Willis (Humphrey et al. 1991), who state that risk and uncertainty are reduced, as BPM maturity increases. Along the same lines, various studies show relations between aspects of company culture and levels in which certain aspects of a company are structured (Ali and Green 2012; Andoh-Baidoo et al. 2012). Consequently, we would expect that there is a positive relation between the uncertainty avoidance index of the country of an organization and the BPM maturity level. Due to the low number of countries involved in this study, it is not possible to show this relation in its general form.

Concerning the relation between the age of an organization and maturity, numerous theories - often labeled 'life cycle theories' - exist about the way organizations develop as they exist longer. Quinn and Cameron (1983) were among the first to compare several of these life cycle models. Based on this comparison they defined a general model that comprises of the common characteristics of other life cycle models. Their model identifies four stages in the life cycle of a organization. The first two stages are mainly characterized by "lots of ideas", "little planning and coordination", an "informal communication structure" and "high innovation", while the latter stages are characterized by the "formalization of rules", "stable structures", "emphasis on efficiency and maintenance", "conservatism" and "institutionalized procedures". Clearly, the characteristics of the latter stages bear a strong resemblance to the higher levels of BPM maturity. Other scholars have presented life cycle models that have a similar relation to BPM maturity models (Miller and Friesen 1984; Kimberly 1979; Scott 1971). These studies motivate a possible positive relation between the age of an organization and its BPM maturity.

\section{Research method}

To investigate the relations between the concepts introduced in the previous section, we conducted a survey. The 
survey consisted of questions that operationalized the constructs of 'BPM maturity', 'performance', 'innovativeness', 'size', 'region', and 'age'. These questions are presented in Appendix A.

For BPM maturity, we had to define our own measurement instrument. For the other constructs, we took measurement instruments from related work. The measures that we took to ensure construct and content validity are based on the heurstics for ensuring validity in IS research that are proposed by Straub et al. (2004). In particular, for each of the constructs, we ensured:

content validity, by aligning the questions with existing measurement instruments from literature, as described in more detail below, and by having the questions checked for content validity by an expert panel of 12 senior professionals.

construct validity, by analyzing factorial validity, using collinearity and cross-loading analysis, and by analysing common method bias, using Harman's single factor test, of which the results are described in Section 5.

reliability, by analysing the internal consistency of the constructs, using AVE, CR, and Cronbach's Alpha, of which the results are also described in Section 5.

BPM maturity assessment in practice is done with detailed questionnaires, interviews and document analysis. The case studies that are mentioned in Section 3 also use such detailed forms of data collection. For case studies, which study a single case in depth, such detailed forms of analyses are feasible. However, for a broad study, in which many cases are investigated, this is not feasible. Therefore, broad studies, like ours, use less detailed questionnaires. There are several broad studies that have been executed before and that operationalize BPM maturity (see Section 3 and in particular Table 1). However, most of these questionnaires operationalize the construct for a particular group of processes, most notably software development processes, while this paper considers maturity to business processes in general. Two prior studies (Raschke and Ingraham 2010; Škrinjar et al. 2008) also target business process in general. However, the first of these studies (Škrinjar et al. 2008) is based on a construct called 'Business Process Orientation' (McCormack et al. 2009) that is related to, but not the same as, BPM maturity. The second of these studies (Raschke and Ingraham 2010) is close to research reported on in this paper. However, they operationalize the construct with one question per level, while we preferred to have multiple questions per maturity level, because this would allow us to do factor analysis for each maturity level and, therewith, provide us with a more accurately validated measurement instrument. Therefore, we decided to develop our own measurement scale, based on the BPMM (Object Management Group 2008). By carefully studying each of the maturity levels that are defined in detail in this specification, we developed three questions per maturity level. The questions were tested in a pilot survey, in which 12 senior professionals filled out the questions and were asked to give feedback on them. The results of the pilot survey were used to fine-tune the questions.

While there exist many different instruments for measuring organizational performance, we chose an operationalization that was used before when researching the relation between maturity and organizational performance. Our operationalization of performance follows the one used by Lockamy III \& McCormack (2004) to rate supply chain management performance. We made only slight adaptations to the questions in that operationalization, to make them specific for an organization as a whole rather than just the supply chain management function of the organization.

As operationalization of innovativeness, we used the one that was proposed by Moorman (1995). We added a fifth (control) question to the four that Moorman already proposes.

To operationalize the construct of organization size, we rely on the definition of organization size that is given by the European Commission (2003) and widely used in Europe. The European Commission classifies organizations as micro, small, medium and large, based on the number of employees, turnover and balance sheet total. Table 2 provides an overview of the definitions of each of these different classes.

We obtain the country in which the organization is based through the contact details that we used to contact respondents. Therefore, it is not necessary to explicitly add a question to the survey about the country in which the organization is based. We added a dummy variable that is 1 when the organization is German and 0 when it is Dutch.

The age of the organization is operationalized by the simple question "How long does your organization exist?".

The survey was sent to quality managers and process managers from 2708 German and Dutch organizations that were on commercially available contact lists (esp.: Kompass and Werzumwem). Quality managers and process managers were targeted, because they can be assumed to have good knowledge of the concepts related to BPM in general and

Table 2 Organization size class definitions

\begin{tabular}{llll}
\hline Class & Headcount & Turnover & Balance sheet total \\
\hline Medium & $<250$ & $\leq € 50$ million & $\leq € 43$ million \\
Small & $<50$ & $\leq € 10$ million & $\leq € 10$ million \\
Micro & $<10$ & $\leq € 2$ million & $\leq € 2$ million
\end{tabular}


BPM maturity specifically. Initial response was low at 56 responses after three weeks. After sending out a reminder, this was increased to 164 . Finally, we randomly selected 200 organizations, which we called by phone to ask them to fill out the survey, which led to a total of 176 responses $(6,5 \%)$.

From the 176 received questionnaires, 120 were filled out till the last question. For many of the 56 partially completed questionnaires, a considerable percentage of more than $75 \%$ of the data was missing, such that missing data imputation methods, like mean replacement would significantly bias the results. In such cases the recommendation is to include only complete cases in the analysis (Hair et al. 2010). Therefore, we continued the analysis with the 120 questionnaires that were filled out till the last question.

Concerning internal and external validity of the results, the first thing to notice is the relatively low response rate and high number of incompletely filled-out questionnaires. We attribute the relatively low response rate to the fact that we used an on-line survey, which typically has a lower response rate than a survey via phone or physical mail. In addition, we did not have an e-mail address of an individual for each contact, in which case we addressed the survey to 'the quality manager' and sent it to a general e-mail address. This may have caused the survey to get lost in some organizations. Although the response rate is low at $6.5 \%$, such a low response rate is not uncommon among Internet surveys nowadays. In a meta-analysis of Internet surveys (Shih and Fan 2009), 4 out of 35 surveys had the same or a lower response rate as our survey. In addition, more important than the response rate, is the question whether the opinion of the respondents is also representative for the non-respondents. A common way to test this, is to test the early response bias (Armstrong and Overton 1977). We tested the early response bias by comparing the demographics (organization size, age, country and industry) of early respondents to those of late respondents, using t-tests. We did not find any significant differences. Therefore, we conclude that there is no early response bias in our data. The relatively high number of incomplete questionnaires indicates a threat to the internal validity of the questionnaire; it is possible that the respondents did not understand the questionnaire and therefore did not complete it, which also raises doubts as to whether the respondents that did complete the questionnaire understood it. However, our expert panel encountered no serious problems with understanding the questionnaire. In addition, we sent the questionnaire to quality and process managers, who can be assumed to be familiar with the concepts that are addressed by the questionnaire. To check whether the questionnaires were indeed filled out by quality and process managemers, we used the contact details of the respondents to obtain that information at a later moment, because we did not ask the respondents for that information through the questionnaire. As not all respondents provided their contact details, we did not retrieve the functions of all respondents, but for a set of 30 respondents. Of these respondents, 6 were quality managers and 24 were managers in general, as shown in Table 3 . While none of the respondents were 'process manager', they were all managers and can therefore be assumed to have a general understanding of business process management.

\section{Results}

Table 3 presents general descriptive statistics about the received responses, showing the size of the organization in terms of the number of employees, the age of the organization, the country in which the organization is based and the industry sector in which the organization operates. The table shows that the organizations that responded are slightly skewed towards smaller and older organizations

Table 3 General information about respondents

\begin{tabular}{|c|c|c|}
\hline \multirow[t]{5}{*}{ Size (employees) } & $1-10$ & 26 \\
\hline & $10-50$ & 38 \\
\hline & $50-250$ & 30 \\
\hline & $250-750$ & 8 \\
\hline & $750-$ & 18 \\
\hline \multirow[t]{5}{*}{ Age (years) } & $0-5$ & 3 \\
\hline & $5-10$ & 12 \\
\hline & $10-20$ & 35 \\
\hline & $20-40$ & 29 \\
\hline & $40-$ & 41 \\
\hline \multirow[t]{2}{*}{ Country } & Germany & 72 \\
\hline & Netherlands & 48 \\
\hline \multirow[t]{11}{*}{ Industry } & Mechanics & 43 \\
\hline & Electronics & 17 \\
\hline & $\mathrm{R} \& \mathrm{D}$ & 7 \\
\hline & Life Science & 2 \\
\hline & Chemicals & 11 \\
\hline & Construction & 2 \\
\hline & Food processing & 3 \\
\hline & Solar & 7 \\
\hline & Automotive & 12 \\
\hline & Services & 9 \\
\hline & Unclassified & 7 \\
\hline \multirow[t]{3}{*}{ Function } & Quality Manager & 6 \\
\hline & Manager & 24 \\
\hline & Process Manager & 0 \\
\hline
\end{tabular}


organizations. It also shows that the majority of the respondents were from the area of mechanics. Most importantly, it shows that the respondents were only from Germany and The Netherlands. These demographics indicate a possible threat to the external validity of the results, in particular with respect to the focus on two countries. Nonetheless, the results can be considered to be representative for these two countries and to a lesser extent for countries with similar organizational cultures (as measured using Hofstede's cultural dimensions (Hofstede 1980)), such as the United States.

Before we started the analysis, we recoded the answers to questions M11, M12 and M13, because these variables are negatively formulated: scoring high on these questions implies low BPM maturity, whereas for the other Mxx questions scoring high implies high BPM maturity. At level 1 we did for instance not ask "there are formal procedures for the execution of tasks in our organizations", but rather the opposite: "formal procedures for the execution of processes do not exist in our organization". We recoded the answers of M11, M12 and M13 as 6 - Mxx (1 becomes 5, 2 becomes $4, \ldots)$.

We used a partial least squares (PLS) approach to test our relations, using the tool SmartPLS (Ringle et al. 2005). PLS does not place strong requirements on the (normal) distribution of the answers (Chin 1998). However, it does place requirements on the sample size and the collinearity of the variables. We analyzed requirements on the sample size by doing a power analysis, using the $\mathrm{G}^{*}$ Power tool. When requiring a medium effect size (of 0.15 ), an alpha error probability of 0.05 , a power of 0.80 and 4 predictor variables, a sample size of 85 is required. Doing a posthoc analysis with 120 respondents we obtain high statistical power at 0.93 .

To test for collinearity, we use the Variance Inflation Factor (VIF) criterion. The collinearity tests show collinearity between the maturity levels. In particular, levels 2, 3, 4 and 5 had a VIF above 3 (at 3.25, 4.51, 4.03, and 3.10 respectively). To remove collinearity, we removed the constructs for levels 3 and 4, which had the highest VIF. Table 4 shows

Table 4 Collinearity statistics

\begin{tabular}{lll}
\hline Construct & VIF & $(1 / \mathrm{VIF})$ \\
\hline Maturity level 1 & 1.28 & 0.78 \\
Maturity level 2 & 2.19 & 0.46 \\
Maturity level 5 & 2.46 & 0.41 \\
Age & 1.22 & 0.82 \\
Innovativeness & 1.55 & 0.65 \\
Performance & 1.31 & 0.77 \\
Region & 1.09 & 0.92 \\
Size & 1.18 & 0.85 \\
\hline
\end{tabular}

the VIF and tolerance (1/VIF) for each of our constructs after we removed these constructs. It shows that none of the constructs have a VIF larger than 3 . Therefore, we conclude that after removing the constructs for maturity level 3 and 4 from the analysis, there is no more collinearity. Unfortunately, this also means that we cannot study maturity level 3 and 4 any further.

For the remaining constructs, we did a confirmatory factor analysis, by first analyzing the factor loadings. Based on this analysis, we eliminated M11, P2, and P6 because their factor loadings were below the recommended threshold value of 0.7. After removing these indicators, all factor loadings exceeded this value, as shown in Table 5. All factor loadings are significant at $p<0.001$. We determined the reliability of the constructs using AVE, composite reliability (CR), and Cronbach's alpha. As shown in Table 5, typical recommended threshold values of 0.5 for AVE, 0.7 for composite reliability, and 0.7 for Cronbach's alpha are exceeded by all constructs. Table 6 shows the descriptive statistics for the constructs. Appendix B also shows the cross-loadings of all variables. The appendix shows that there is substantial cross-loading of variables belonging to maturity levels 2, 3, 4 and 5 onto other factors. This is expected, as we also identified collinearity between these the related factors, for which reason we removed the factors for maturity levels 3 and 4 from our analysis.

To test for common method bias, we performed Harman's single factor test. The test showed a single factor that explained $24 \%$ of the variance. This is well below the $50 \%$ threshold, such that we can assume that common method bias is not a problem for our data.

Finally, the relations were tested using PLS, performing bootstrapping with resampling to 1000 cases. Figure 3 shows the results of the data analysis. For readability, only significant relations are shown in the figure. For completeness, Appendix $\mathrm{C}$ shows all path coefficients. We tested the model for nonlinear effects, moderators and mediators, but did not find any.

\section{Discussion}

Below, we discuss the results in detail. First discussing the relation between maturity and performance. Second, discussing the relation between innovativeness and maturity. Third, discussing the relations between the other properties - age, size and region - and maturity, and finally discussing additional relations that can be found in the data.

\subsection{BPM maturity and performance}

The figure shows a positive relation between BPM maturity level 2 and performance at the 0.05 level. This is in line 
Table 5 Factor analysis of constructs

\begin{tabular}{|c|c|c|c|c|c|c|c|c|c|c|}
\hline \multirow[b]{2}{*}{ Construct } & \multirow[b]{2}{*}{ Variable } & \multicolumn{6}{|c|}{ Factor loadings } & \multirow[b]{2}{*}{ AVE } & \multirow[b]{2}{*}{$\mathrm{CR}$} & \multirow[b]{2}{*}{ alpha } \\
\hline & & Mat1 & Mat2 & Mat3 & Per & Inn & Size & & & \\
\hline \multirow{2}{*}{$\begin{array}{l}\text { Maturity level } 1 \\
\text { (Mat1) }\end{array}$} & M12 recoded & $0.95^{*}$ & & & & & & 0.80 & 0.89 & 0.77 \\
\hline & M13 recoded & $0.84^{*}$ & & & & & & & & \\
\hline \multirow{3}{*}{$\begin{array}{l}\text { Maturity level } 2 \\
\text { (Mat2) }\end{array}$} & M21 & & $0.93^{*}$ & & & & & 0.82 & 0.93 & 0.89 \\
\hline & M22 & & $0.90^{*}$ & & & & & & & \\
\hline & M23 & & $0.88^{*}$ & & & & & & & \\
\hline \multirow{3}{*}{$\begin{array}{l}\text { Maturity level } 5 \\
\text { (Mat5) }\end{array}$} & M51 & & & $0.79^{*}$ & & & & 0.64 & 0.84 & 0.73 \\
\hline & M52 & & & $0.84^{*}$ & & & & & & \\
\hline & M53 & & & $0.77^{*}$ & & & & & & \\
\hline \multirow{4}{*}{$\begin{array}{l}\text { Performance } \\
\text { (Per) }\end{array}$} & $\mathrm{P} 1$ & & & & $0.75^{*}$ & & & 0.57 & 0.87 & 0.80 \\
\hline & P3 & & & & $0.78^{*}$ & & & & & \\
\hline & $\mathrm{P} 4$ & & & & $0.84^{*}$ & & & & & \\
\hline & P5 & & & & $0.85^{*}$ & & & & & \\
\hline \multirow{5}{*}{$\begin{array}{l}\text { Innovativeness } \\
\text { (Inn) }\end{array}$} & I1 & & & & & $0.76^{*}$ & & 0.61 & 0.89 & 0.84 \\
\hline & I2 & & & & & $0.76^{*}$ & & & & \\
\hline & $\mathrm{I} 3$ & & & & & $0.84^{*}$ & & & & \\
\hline & I4 & & & & & $0.72 *$ & & & & \\
\hline & I5 & & & & & $0.81^{*}$ & & & & \\
\hline \multirow[t]{3}{*}{ Size } & $\mathrm{S} 1$ & & & & & & $0.88^{*}$ & 0.83 & 0.93 & 0.94 \\
\hline & $\mathrm{S} 2$ & & & & & & $0.85^{*}$ & & & \\
\hline & S3 & & & & & & $0.99^{*}$ & & & \\
\hline
\end{tabular}

*All loadings are significant at $p<0.001$

with results that were presented in previous studies. However, this study shows a relation between BPM maturity and the performance of the organization as a whole, where previous studies show the relation between BPM maturity and the performance of the process that is improved. In this way, this paper presents a scientific contribution that has important practical implications as well, because these results provide convincing evidence that can be used to get the support of higher management to engage in a project to improve BPM maturity.

Interestingly there is no evidence that level 5 has a further positive impact. Due to problems with collinearity with respect to levels 3 and 4, nothing conclusive can be said for those levels. We conclude that there is evidence that it pays off to develop the BPM capability of an organization and to improve the level of maturity to at least level 2 .

The figure shows that $10 \%$ of the variance in performance can be explained by BPM maturity. The fact that this number is relatively low, can easily be explained, because clearly BPM maturity is not the only property to contribute to organizational performance. Many other properties affect organizational performance, including properties that can be influenced, such as employee motivation, strategic decisions and marketing expenses, and properties that cannot be influenced, such as investment climate and other macroeconomic conditions. Indeed, if we relate innovativeness, size, age and region to performance, the $R^{2}$ already becomes 0.24 .

Table 6 Descriptive statistics of constructs

\begin{tabular}{lllllc} 
Construct & Mean & Std. deviation & Median & Skewness & Kurtosis \\
\hline Maturity level 1 & 4.0 & 1.1 & 4.0 & -1.0 & 0.0 \\
Maturity level 2 & 3.7 & 1.2 & 4.0 & -0.7 & -0.4 \\
Maturity level 5 & 3.5 & 1.2 & 4.0 & -0.6 & -0.6 \\
Performance & 3.5 & 0.8 & 4.0 & -0.3 & 0.0 \\
Innovativeness & 3.5 & 1.0 & 4.0 & -0.4 & -0.4 \\
Size & 2.5 & 1.1 & 2.0 & 0.4 & -0.4 \\
Age & 3.8 & 1.1 & 4.0 & -0.5 & -0.7 \\
\hline
\end{tabular}


Fig. 3 PLS results (only significant relations shown)

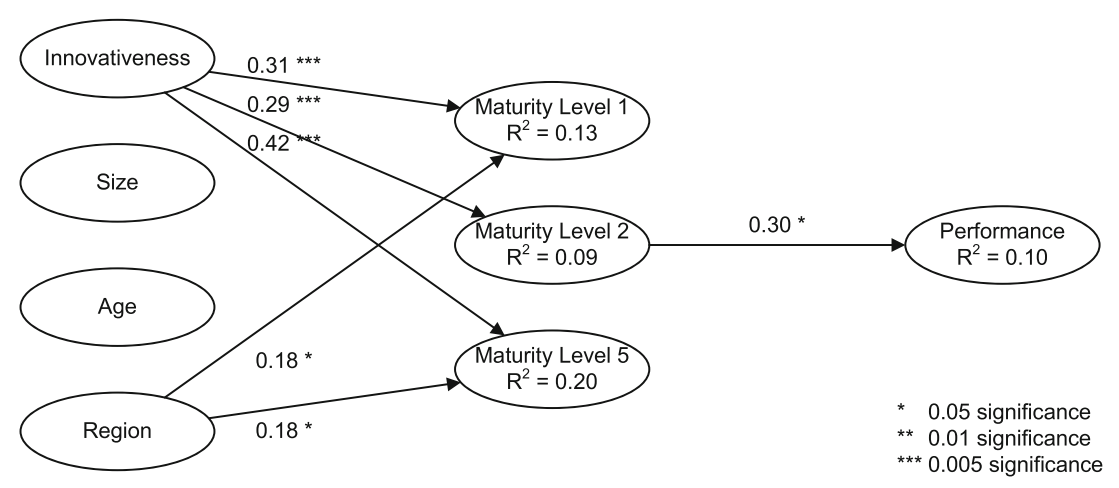

\subsection{Innovativeness and BPM maturity}

The figure shows positive relations between innovativeness and all levels of BPM maturity at the 0.005 level. This result is difficult to interpret, as it means that organizations that are more innovative are more at all levels of maturity. This can be explained, because, theoretically a level of maturity also includes all properties of the lower levels (Object Management Group 2008), i.e.: if an organization is at level 5 it does everything that it needs to do at level 5 , but also everything that it needs to do at level 1,2,3 and 4. Therefore, we interpret the result as: organizations that are more innovative are more at maturity level 5 .

This contradicts popular belief, as made explicit in literature, that more mature organizations have more rigid processes that hamper their ability to be innovative. Rather, it provides evidence to the contrary: there is a positive relation between an organization's innovativeness and its BPM maturity level. This relation finds support from Nelson (1991), who emphasizes the role of organizational and procedural capabilities in generating innovations. According to Nelson, organizations with a superior organization of internal processes are more successful in generating innovations and subsequently profiting from those innovations. Since, a higher BPM maturity level is directly linked to a superior organization of processes, this implies that having a higher maturity level means more innovation. Considering that this motivates a relation from BPM maturity to innovation (rather than from innovation to BPM maturity), it is also interesting to test this relation empirically. Looking at the empirical data, there indeed is a positive relation (of 0.37) at the 0.005 level between maturity level 5 and innovativeness, meaning that organizations that are at level 5 are more innovative. This finding is consistent with a similar analysis by Benner and Tushman (2002) who found that increased routinization associated with process management leads to increased innovation. It is also possible that BPM maturity is a precondition for successfully transforming ideas into profit, such that innovative organizations are successful by adopting processes for introducing their innovations into the market. Innovative organizations that do not adopt processes for exploiting their innovations would then either be less successful in terms of performance, or even go bankrupt, in which case they would not appear in the dataset. Reasoning this way, there is a relation between innovation, via BPM maturity, with performance. When inspecting the data, we see that this is indeed the case. There is a positive relation between innovativeness and performance (of 0.37 ) at the 0.001 level. So, the data shows that innovativeness of an organization and BPM maturity influence each other positively, while both also have a positive effect on the performance of an organization as a whole. However, how exactly this mechanism of mutual positive influence works, remains as a topic for future study.

Another possible explanation for this unexpected result is that the relation is moderated by the type of innovation. In related work, Sethi and Iqbal (2008) show that while structured (stage-gate) processes for innovation have a positive effect on the performance of incremental innovations, but that they have a negative effect on the performance of radical innovations. This would explain why organizations that work on radical innovations strive to have a lower BPM maturity, while organizations that work on incremental innovations strive to have a higher BPM maturity.

\subsection{Other properties and BPM maturity}

Of the other properties - age, size and region - that we expect to influence BPM maturity, we only found a relation between region and level of maturity. Thus we can say that there is a relation between the country of origin of an organization and its BPM maturity level.

That there was no relation between organization size and BPM maturity was surprising to us, because larger organization have more resources to engage in process innovation projects and, in addition, larger organizations have a more pressing need to manage their processes more strictly. We did not find a satisfactory explanation for this result. Therefore, this remains as a topic for future study. 
That we did not find a relation between age of an organization and BPM maturity is less surprising, because we made the explicit assumption that organizations that are older are also in the later stages of organizational development, while there is no guarantee that this is indeed the case. Consequently, a better claim to investigate would have been that organizations that are in the later stages of organizational development have higher levels of maturity. This remains as a topic for future work.

For each of the levels of maturity only $20 \%$ or less of the variance can be explained by innovativeness, size, age and region. This is not surprising. We expect many other properties to influence the desire and ability of organizations to increase their BPM maturity and some of these properties, such as for example management style, are likely to have a stronger effect on BPM maturity than the properties that we studied. Indeed, rather than presenting an exhaustive collection of the properties that influence BPM maturity, it was the goal of this paper to investigate properties that can be used by an organization for benchmarking, such that it is possible for organizations to check what the maturity level is of organizations that are similar to them. For this purpose, the chosen properties represent an interesting subset.

\subsection{Additional findings}

We investigated the data for further interesting relations that can be used for further study. We found two interesting relations. First, we found a relation (of 0.34) at the 0.001 level between age and size of an organization, leading to the unsurprising result that organizations tend to grow as they exist longer. Second, we found a negative relation (of -0.20) at the 0.05 level between age and innovativeness, meaning that as organizations exist longer, they tend to become less innovative. Though more surprising, this finding is supported at least to an extent by a previous more in-depth study about the relation between innovativeness and age. This study finds that older organizations tend to create more innovative products, but in younger organizations innovative products have more impact on the turnover of the organization (Avermaete et al. 2003).

\section{Conclusions}

Through an empirical study this paper answered two research questions: how BPM maturity affects overall business performance; and which properties of an organization determine what the best level of BPM maturity for an organization is, in particular focusing on size, age, region and innovativeness of the organization. These research questions were answered through an survey that was conducted among 120 organizations in Germany and The Netherlands.

\subsection{Findings}

The study showed that there is a significant positive relation between BPM maturity level 2 and organizational performance, such that organizations that operate at that level of BPM maturity can be expected to perform better. This finding has important practical implications, because basically it means that it pays off to develop the BPM capability of an organization. Relations between BPM maturity levels 3 and 4 and BPM maturity could not be studied, due to problems with collinearity of the data. Therefore, cannot determine whether reaching those levels pays off further. No relation was found between BPM maturity level 5 and organizational performance, leading to doubts as to whether it pays off to reach that level.

The study investigated whether the region, age, size and innovativeness of an organization influence the level of maturity that that organization has. This result can be used as a benchmark, because for organizations of different origin, size, age and product type, a different BPM maturity level may be appropriate. With respect to these properties, we found a relation between innovativeness and maturity level, meaning that more innovative organizations typically have a higher maturity level. In addition, we found a relation between region and maturity level. There is no evidence to suggest that organizations have, or should have, a very different attitude towards BPM maturity, depending on their size or age. However, innovative organizations do appear to strive for higher BPM maturity.

Interestingly, this last finding contradicts popular belief that higher levels of maturity are associated with more rigid processes that hamper, rather than stimulate, innovativeness. We did not find strong evidence in the literature that this should be otherwise. However, looking in more detail at the results from this study, there is strong support for the observation that innovativeness and BPM maturity have a positive influence on each other and that both have a positive influence on organizational performance.

While the study focused on the innovativeness, region, size and age, we acknowledge that other properties influence BPM maturity as well. This is also illustrated by the $R^{2}$ in the analysis, which is far below 1.0, showing that the variance in BPM maturity is not completely explained by the properties that were chosen. Consequently, in future work, other properties that may influence maturity can be studied as well.

\subsection{Limitations and future work}

Although the number of organizations that responded to the survey was sufficiently large to perform a reliable statistical (PLS) analysis, the response rate was low at $6.5 \%$. 
This may lead to a participation bias in the results. We attribute the relatively low response rate to the fact that we used an on-line survey, which typically has a lower response rate than a survey via phone or physical mail. This may have caused the survey to get lost in some organizations.

The study focuses on innovativeness, region, size and age as properties that determine the level of maturity that an organization should be on to achieve optimal performance. However, the maturity and performance of an organization are not exclusively determined by these properties. It was also not the aim of this study to exhaustively investigate the properties that influence maturity and performance. Rather, the study focused on commonly used properties (age, size and region) and controversial properties (innovativeness). Other properties can be studied in future work.

The performance of organizations was measured in a qualitative manner. An alternative would have been to measure performance using absolute measures, such as turnover and profit. However, this has the drawback that it makes it harder to compare organizations between sectors, because a turnover of 1 million in a sector where organizations are typically large may mean something completely different than the same turnover in a sector where organizations are typically small. In addition, it is not uncommon to determine organizational performance in a questionnaire by means of qualitative questions. The questions that we used were even derived from another study. To increase the practical impact of the study, a relation can be investigated between maturity level, financial performance and cost, to enable organizations to make a trade-off of whether or not to develop the BPM capability of an organization.

With respect to practical impact of the study, the question remains of how much the organization will benefit exactly from an increase in maturity level and whether the investment, that has to be made to increase the maturity level, pays off. Fourth, the measurement model that was developed for measuring BPM maturity was imperfect. In particular, it showed collinearity and cross loadings for maturity levels 3 and 4 , which we had to remove for that reason. This made it impossible to conduct an analysis for maturity levels 3 and 4 . In addition to that a measurement model for BPM maturity has merit in itself, as it can be used in future survey-based research into BPM maturity. However, because of the validity problems, the measurement instrument for BPM maturity that resulted from this research is unfortunately incomplete. Therefore, the measurement instrument for BPM maturity that was developed in this research should be refined, using a more thorough methodology like the one used by Recker and Rosemann (2010).
The study shows a relation between innovativeness, BPM maturity and performance. However, it remains unclear exactly how these three properties influence each other. There is evidence to suggest that innovativeness leads to higher performance, provided that there are processes in place to enable organizations to cash in on their innovativeness. This relation can be investigated in more depth in future work.

\subsection{Implications}

The implications of the findings of this paper are that organizations should strive to reach at least BPM maturity level 2 . While this may seem like a trivial conclusion for researchers, many of the organizations that were surveyed showed evidence that they operated at level 1 , in that they gave level 1 indicators high scores (agree or strongly agree). This is not surprising when we consider that reaching a higher level of maturity, even if it is only level 2, requires a lot of effort, of which the benefits may not always be obvious. However, this study shows that there is evidence that even for small companies this effort is likely to pay off.

The findings also imply that organizations that have a high innovativeness, should strive for high BPM maturity. The reason for this is likely to be, that highly innovative organization that do not have the processes in place to exploit their innovations, cannot obtain the performance increase that is promised by these innovations.

Open Access This article is distributed under the terms of the Creative Commons Attribution License which permits any use, distribution, and reproduction in any medium, provided the original author(s) and the source are credited.

\section{Appendix A: Construct questions}

\section{Business process maturity}

Questions are answered on a 1-5 Likert scale. Level 1 (Initial):

M11 Formal procedures for the execution of processes do not exist in our organization

M12 If procedures are defined, they are rarely followed

M13 Everybody executes tasks in its own way, in other words: everybody has its own methods

Level 2 (Managed):

M21 At the beginning of a project, we make agreements about which methods and technology we will use. 
M22 If we make agreements about work methods, they will be documented such that they can be executed in the same way at another time.

M23 We use planning and management procedures to control our individual projects

Level 3 (Standardized):

M31 Procedures are standardized for the whole organization

M32 Work procedures and objectives are well documented in our whole organization

M33 Processes are defined such that they will be in the same way by different work groups

Level 4 (Predictable):

M41 Performance is managed statistically (e.g. by measuring KPIs) to understand performance and to control variation

M42 Processes/tasks are managed in such a way that they meet agreed-upon performance and quality goals

M43 If processes do not perform according to predefined standards, they are corrected to meet the quantitative goals

Level 5 (Innovating):

M51 Our organization understands its critical business issues and areas of concern by using feedback from performance measurements

M52 Our organization sets quantitative improvement goals to constantly reorganize processes when perceived necessary

M53 We constantly pilot with new ideas and new technologies to improve our processes

\section{Innovativeness}

Questions are answered on a 1-5 Likert scale.

I1 We are more innovative than our competitors in deciding what methods to use in achieving our targets and objectives

I2 We are more innovative than our competitors in initiating new products and systems

I3 We are more innovative than our competitors in developing new ways of achieving our targets and objectives

I4 We are more innovative than our competitors in initiating changes in the job contents and work methods of our staff

I5 Do you consider your company as: a. very conservative, $b$. somewhat conservative, $c$. not conservative and not innovative, d. somewhat innovative, e. very innovative

\section{Performance}

P1 How would you evaluate the overall performance of your organization over the previous year 2011 ?

Rate $1-5$ ( 1 = very bad, $5=$ very good $)$

P2 Rate the overall performance of your business (unit) in the past year

Rate $1-5$ ( $1=$ very bad, $5=$ very good $)$

P3 Rate the overall performance of your business (unit) in the past year relative to your competitors

Rate 1-5 ( $1=$ much worse, $5=$ much better $)$

P4 Rate the overall profitability compared to your competitors

Rate 1-5 ( $1=$ much worse, $5=$ much better $)$

P5 Compared to your competitors, you met your overall goals

Rate $1-5$ ( $1=$ much worse, $5=$ much better $)$

P6 Compared to your competitors, the quality of the process output is

Rate $1-5(1=$ much worse, $5=$ much better $)$

\section{Size}

S1 How many employees does your organization count? a. $1-10$, b. $10-50$, c. $50-250$, d. $250-750$, e. more than 750

S2 How large was the turnover in the previous year (2011, in euro's)?

a. less than 2 million, b. 2-10 million, c. $10-50$ million, d. more than 50 million

S3 What definition fits your company best?

a. very small (micro), b. small, c. medium-sized, d. large, e. very large

Age

A1 How long does your organization exist? 


\section{Appendix B: Variable Cross Loadings}

\begin{tabular}{|c|c|c|c|c|c|c|c|c|c|c|}
\hline Variable & Mat1 & Mat2 & Mat3 & Mat4 & Mat5 & Per & Inn & Size & Age & Region \\
\hline M11 recoded & 0.41 & 0.25 & 0.34 & 0.38 & 0.32 & -0.10 & -0.01 & 0.16 & -0.08 & 0.04 \\
\hline M12 recoded & 0.95 & 0.30 & 0.33 & 0.39 & 0.38 & 0.19 & 0.31 & 0.06 & 0.11 & 0.11 \\
\hline M13 recoded & 0.84 & 0.31 & 0.28 & 0.36 & 0.34 & 0.09 & 0.13 & 0.02 & 0.08 & 0.16 \\
\hline M21 & 0.29 & 0.93 & 0.72 & 0.65 & 0.68 & 0.31 & 0.27 & 0.05 & 0.05 & 0.01 \\
\hline M22 & 0.30 & 0.90 & 0.72 & 0.58 & 0.57 & 0.23 & 0.18 & -0.11 & 0.01 & 0.01 \\
\hline M23 & 0.32 & 0.88 & 0.71 & 0.68 & 0.65 & 0.19 & 0.26 & 0.06 & 0.02 & 0.03 \\
\hline M31 & 0.30 & 0.68 & 0.88 & 0.66 & 0.64 & 0.10 & 0.23 & 0.02 & 0.07 & -0.15 \\
\hline M32 & 0.35 & 0.73 & 0.92 & 0.80 & 0.66 & 0.19 & 0.32 & 0.10 & 0.10 & 0.01 \\
\hline M33 & 0.26 & 0.70 & 0.88 & 0.70 & 0.65 & 0.20 & 0.27 & 0.09 & -0.02 & -0.06 \\
\hline M41 & 0.32 & 0.65 & 0.73 & 0.91 & 0.68 & 0.15 & 0.30 & 0.30 & 0.06 & -0.01 \\
\hline M42 & 0.39 & 0.60 & 0.72 & 0.92 & 0.69 & 0.02 & 0.31 & 0.04 & -0.05 & 0.10 \\
\hline M43 & 0.43 & 0.64 & 0.75 & 0.85 & 0.68 & 0.15 & 0.21 & 0.02 & 0.05 & 0.13 \\
\hline M51 & 0.36 & 0.69 & 0.74 & 0.80 & 0.79 & 0.07 & 0.15 & 0.07 & 0.08 & 0.23 \\
\hline M52 & 0.36 & 0.57 & 0.63 & 0.75 & 0.84 & 0.12 & 0.30 & 0.14 & 0.05 & 0.10 \\
\hline M53 & 0.27 & 0.49 & 0.45 & 0.37 & 0.77 & 0.19 & 0.40 & 0.02 & 0.00 & -0.01 \\
\hline P1 & 0.15 & 0.27 & 0.17 & 0.07 & 0.10 & 0.75 & 0.27 & 0.05 & 0.02 & -0.08 \\
\hline P2 & 0.05 & -0.02 & 0.02 & 0.03 & 0.08 & 0.40 & 0.19 & -0.07 & 0.08 & -0.05 \\
\hline P3 & 0.05 & 0.11 & 0.04 & -0.01 & -0.01 & 0.78 & 0.30 & 0.25 & 0.11 & -0.15 \\
\hline P4 & 0.11 & 0.19 & 0.17 & 0.10 & 0.10 & 0.84 & 0.26 & 0.09 & 0.20 & -0.01 \\
\hline P5 & 0.13 & 0.25 & 0.21 & 0.13 & 0.13 & 0.85 & 0.35 & 0.08 & 0.06 & -0.06 \\
\hline P6 & 0.22 & 0.18 & 0.13 & 0.15 & 0.20 & 0.52 & 0.27 & -0.16 & -0.06 & 0.19 \\
\hline I1 & 0.06 & 0.19 & 0.18 & 0.10 & 0.30 & 0.27 & 0.76 & -0.04 & -0.22 & -0.11 \\
\hline $\mathrm{I} 2$ & 0.14 & 0.12 & 0.15 & 0.08 & 0.15 & 0.32 & 0.76 & 0.00 & -0.14 & -0.18 \\
\hline I3 & 0.29 & 0.13 & 0.22 & 0.22 & 0.21 & 0.34 & 0.84 & -0.12 & -0.14 & -0.12 \\
\hline I4 & 0.28 & 0.23 & 0.32 & 0.39 & 0.34 & 0.22 & 0.72 & -0.12 & -0.01 & -0.05 \\
\hline I5 & 0.20 & 0.31 & 0.28 & 0.29 & 0.38 & 0.36 & 0.81 & -0.02 & -0.24 & -0.07 \\
\hline $\mathrm{S} 1$ & 0.08 & -0.03 & 0.00 & 0.12 & 0.01 & 0.07 & -0.10 & 0.88 & 0.32 & 0.01 \\
\hline S2 & 0.05 & -0.05 & 0.04 & 0.11 & 0.02 & 0.15 & -0.07 & 0.85 & 0.33 & -0.01 \\
\hline S3 & 0.04 & 0.05 & 0.13 & 0.18 & 0.15 & 0.07 & -0.08 & 0.99 & 0.31 & 0.11 \\
\hline A1 & 0.11 & 0.03 & 0.06 & 0.02 & 0.04 & 0.09 & -0.19 & 0.34 & 1.00 & 0.05 \\
\hline $\mathrm{R}$ & 0.14 & 0.02 & -0.07 & 0.07 & 0.11 & -0.04 & -0.12 & -0.06 & 0.05 & 1.00 \\
\hline
\end{tabular}

All cross loadings (in boldface) are significant at $p<0.001$ 


\section{Appendix C: PLS Path Coefficients}

\begin{tabular}{ll} 
Path & $\begin{array}{l}\text { Coefficient } \\
\text { (Significance) }\end{array}$ \\
\hline
\end{tabular}

\begin{tabular}{ll}
\hline Age $\rightarrow$ Maturity Level 1 & 0.15 \\
Age $\rightarrow$ Maturity Level 2 & 0.07 \\
Age $\rightarrow$ Maturity Level 5 & 0.07 \\
Innovativeness $\rightarrow$ Maturity Level 1 & $0.31^{* * *}$ \\
Innovativeness $\rightarrow$ Maturity Level 2 & $0.29^{* * *}$ \\
Innovativeness $\rightarrow$ Maturity Level 5 & $0.42^{* * *}$ \\
Maturity Level 1 $\rightarrow$ Performance & 0.03 \\
Maturity Level 2 $\rightarrow$ Performance & $0.30^{*}$ \\
Maturity Level 5 $\rightarrow$ Performance & -0.25 \\
Region $\rightarrow$ Maturity Level 1 & $0.18^{*}$ \\
Region $\rightarrow$ Maturity Level 2 & 0.05 \\
Region $\rightarrow$ Maturity Level 5 & $0.18^{*}$ \\
Size $\rightarrow$ Maturity Level 1 & 0.04 \\
Size $\rightarrow$ Maturity Level 2 & 0.04 \\
Size $\rightarrow$ Maturity Level 5 & 0.15
\end{tabular}

$* 0.05$ significance

** 0.01 significance

$* * * 0.005$ significance

\section{References}

Adler, P., McGarry, F., Irion-Talbot, W., \& Binney, D. (2005). Enabling process discipline: lessons from the journey to CMM Level 5. MISQ Executive, 4(1), 215-227.

Ahmed, F., \& Capretz, L.F. (2011). A business maturity model of software product line engineering. Information Systems Frontiers, 13, 543-560.

Ali, S., \& Green, P. (2012). Effective information technology (IT) governance mechanisms: An IT outsourcing perspective. Information Systems Frontiers, 14, 179-193.

Andersen, K.V., \& Henriksen, H.Z. (2006). E-government maturity models: Extension of the Layne and Lee model. Government Information Quarterly, 23(2), 236-248.

Andoh-Baidoo, F.K., Osei-Bryson, K.-M., \& Amoako-Gyampah, K. (2012). Effects of firm and IT characteristics on the value of e-commerce initiatives: An inductive theoretical framework. Information Systems Frontiers, 14, 237-259.

Antoniol, G., Gradara, S., \& Venturi, G. (2004). Methodological issues in a CMM Level 4 implementation. Software Process: Improvement and Practice, 9(1), 33-50.

Armstrong, J.S., \& Overton, T.S. (1977). Estimating nonresponse bias in mail surveys. Journal of Marketing Research, 14, 396-402.

Avermaete, T., Viaene, J., Morgan, E.J., \& Crawford, N. (2003). Determinants of innovation in small food firms. European Journal of Innovation Management, 6(1), 8-17.

Batenburg, R., \& Versendaal, J. (2008). Maturity matters: Performance determinants of the procurement business function. In Proceedings of the 16th european conference on information systems (Vol. 1 pp. 563-574). Ireland: Galway.

Becker, J., Knackstedt, R., \& Pöppelbuß, J. (2009). Developing maturity models for it management. Business \& Information Systems Engineering, 1(3), 213-222.
Benner, M., \& Tushman, M. (2002). Process management and technological innovation: a longitudinal study of the photography and paint industries. Administrative Science Quarterly, 47, 676-706.

Bowers, P. (2002). The F/A-18 advanced weapons lab successfully delivers a \$ 120-million software block upgrade. CrossTalk, 15(1), $10-11$.

Chin, W. (1998). The partial least squares approach to structural equation modeling. In Modern methods for business research (pp. 295-336). New Jersey: Lawrence Erlbaum Associates.

Cho, H.J., \& Pucik, V. (2005). Relationship between innovativeness, quality, growth, profitability, and market value. Strategic Management Journal, 26(6), 555-575.

CMMI Institute (2011). CMMI Version 1.3 Information Center. Retrieved 23 July 2013 from: http://cmmiinstitute.com/.

Cooper, R.G. (1990). Stage-gate system: a new tool for managing new products. Business Horizons, 44-54.

Crosby, P. (1979). Quality is free. New York: McGraw-Hill.

Davenport, T. (1993). Process innovation: reengineering work through information technology. Boston: Harvard Business School Press.

De Bruin, T., Rosemann, M., Freeze, R., \& Kulkarni, U. (2005a). Understanding the main phases of developing a maturity assessment model. In Australasian Conference on Information Systems (pp. 8-19). Australasian chapter of the association for information systems.

De Bruin, T., \& Rosemann, M. (2005b). Towards a business process management maturity model. In Proceedings of the 13th european conference on information systems. Germany: Regensburg.

De Bruin, T., \& Rosemann, M. (2010). Using the Delphi technique to identify BPM capability areas. In Australasian Conference on Information Systems (pp. 642-653). Australasian chapter of the association for information systems.

Deephouse, C., Goldenson, D., Kellner, M., \& Mukhopahyay, T. (1995). The effects of software processes on meeting targets and quality. In Proceedings of the 28th annual Hawaii international conference on system sciences (pp. 710-719). Maui: Hawaii, USA.

Diaz, M., \& King, J. (2002). How CMM impacts quality, productivity, rework, and the bottom line. CrossTalk, 15(3), 9-14.

Diaz, M., \& Sligo, J. (1997). How software process improvement helped Motorola. IEEE Software, 14(5), 75-81.

Dion, R. (1992). Elements of a process-improvement program. Software, IEEE, 9(4), 83-85.

Dion, R. (1993). Process improvement and the corporate balance sheet. Software, IEEE, 10(4), 28-35.

Dooley, K., Subra, A., \& Anderson, J. (2001). Maturity and its impact on new product development project performance. Research in Engineering Design, 13(1), 23-29.

Dumas, M., La Rosa, M., Mendling, J., \& Reijers, H.A. (2013). Fundamentals of business process management. Berlin-Heidelberg: Springer.

European Commission (2003). Commission Recommendation of 6 May 2003 concerning the definition of micro, small and mediumsized enterprises. Tech. rep., European Commission Document Number C(2003) 1422.

Filbeck, G., Swinarski, M., \& Zhao, X. (2013). Shareholder reaction to firm investments in the capability maturity model: an event study. European Journal of Information Systems, 22(2), 170-190.

Gibson, D.L., Goldenson, D.R., \& Kost, K. (2006). Performance Results of CMMI -Based Process Improvement. Tech. Rep. August, Software Engineering Institute.

Goldenson, D.R., El Emam, K., Herbsleb, J., \& Deephouse, C. (1999). Empirical Studies of Software Process Assessment Methods. In Elements of software process assessment and improvement (Vol. 47). Los Alamitos, CA: IEEE Computer Society Press. 
Hair, J., Black, W., Babin, B., \& Anderson, R. (2010). Multivariate data analysis; a global perspective. London: Pearson.

Hammer, M. (2007). The Process Audit. Harvard business review.

Harter, D.E., Krishnan, M.S., \& Slaughter, S.A. (2000). Effects of process maturity on quality, cycle time, and effort in software oroduct development. Management Science, 46(4), 451-466.

Herbsleb, J., \& Goldenson, D. (1996). A systematic survey of CMM experience and results. In Proceedings of IEEE 18th International Conference on Software Engineering (pp. 323-330). Los Alamitos: IEEE Computer Society Press.

Herbsleb, J., \& Zubrow, D. (1997). Software Quality and the capability maturity model. Communications of the ACM, 40(6), 30-40.

Hofmann, P., \& Reiner, G. (2006). Drivers for improving supply chain performance: an empirical study. International Journal of Integrated Supply Management, 2(3), 214-230.

Hofstede, G. (1980). Culture's consequences: International differences in work-related values. Thousand Oaks: Sage Publications.

Humphrey, W.S., Snyder, T.R., \& Willis, R.R. (1991). Software process improvement at Hughes aircraft. IEEE Software, 8(4), 1123.

Ibbs, C.W., \& Kwak, Y.H. (2000). Assessing project management maturity. Project Management Journal, 31, 32-4.

Jiang, J.J., Klein, G., Hwang, H.G., Huang, J., \& Hung, S.Y. (2004). An exploration of the relationship between software development process maturity and project performance. Information \& Management, 41(3), 279-288.

Jung, H.w., \& Goldenson, D.R. (2003). CMM-Based Process Improvement and Schedule Deviation in Software Maintenance. Tech. Rep. July. Software Engineering Institute.

Kimberly, J. (1979). Issues in the creation of organizations: Initiation, innovation, and institutionalization. Academy of Management Journal, 22(3), 437-457.

Krasner, H. (2001). Accumulating the body of evidence for the payoff of software process improvement. In Software process improvement (pp. 519-539). Los Alamitos: IEEE Computer Society Press.

Krishnan, M., \& Kellner, M. (1999). Measuring process consistency: implications for reducing software defects. IEEE Transactions on Software Engineering, 25(6), 800-815.

Krishnan, M., \& Kriebel, C. (2000). An empirical analysis of productivity and quality in software products. Management Science, 46(6), 745-759.

Lockamy III, A., \& McCormack, K. (2004). The development of a supply chain management process maturity model using the concepts of business process orientation. Supply Chain Management: An International Journal, 9(4), 272-278.

McCormack, K. (2001). Business process orientation: Do you have it? Quality Progress, 34(1), 51-58.

McCormack, K., Willems, J., Bergh, J.V.D., Deschoolmeester, D., Willaert, P., Štemberger, M.I., Škrinjar, R., Trkman, P., Ladeira, M.B., Oliveira, M.P.V.D., Vuksic, V.B., \& Vlahovic, N. (2009). A global investigation of key turning points in business process maturity. Business Process Management Journal, 15(5), 792-815.

McGarry, F., \& Decker, B. (2002). Attaining level 5 in CMM process maturity. IEEE Software, 19(6), 87-96.

Mettler, T., Rohner, P., \& Winter, R. (2010). Towards a classification of maturity models in information systems. In A. D'Atri, M. De Marco, A.M. Braccini, \& F. Cabiddu (Eds.) Management of the interconnected world SE - 39 (pp. 333-340). Physica-Verlag HD.

Michlmayr, M. (2005). Software process maturity and the success of free software projects. In Proceedings of the 2005 conference on software engineering: evolution and emerging technologies (pp. 3-14). Amsterdam, The Netherlands: IOS Press.

Miller, D., \& Friesen, P.H. (1984). A longitudinal study of the corporate life cycle. Management Science, 30(10), 1161-1183.
Mintzberg, H. (1979). The structuring of organizations. New Jersey: Prentice-Hall Inc.

Moorman, C. (1995). Organizational market information processes: cultural antecedents and new product outcomes. Journal of Marketing Research, 32(3), 318-335.

Nawrocki, J.R., Walter, B., \& Wojciechowski, A. (2002). Comparison of CMM Level 2 and eXtreme Programming. In ECSQ 2002, LNCS (pp. 288-297). New York: Springer.

Nelson, R. (1991). Why do firms differ, and how does it matter? Strategic Management Journal, 12, 61-74.

Niehaves, B., Poeppelbuss, J., Plattfaut, R., \& Becker, J. (2014). BPM capability development - a matter of contingencies. Business Process Management Journal, 20(1), 90-106.

Nolan, R. (1973). Managing the crisis in data processing. Harvard Business Review, 57(2), 115-126.

Object Management Group (2008). Business Process Maturity Model (BPMM). Tech. Rep. June. Object Management Group.

Oldham, L.G., Putman, D.B., Peterson, M., Rudd, B., \& Tjoland, K. (1999). Benefits realized from climbing the CMM ladder. CrossTalk, 12(5), 7-10.

Paulk, M. (1993). Capability maturity model for software. New York: Wiley.

Pitterman, B. (2000). Telcordia technologies: the journey to high maturity. IEEE Software, 17(4), 89-96.

Porter, R.E., \& Detoma, D.A. (1999). A multi-site software process framework. CrossTalk, 12(10), 19-22.

Quinn, R., \& Cameron, K. (1983). Organizational life cycle and shifting criteria of effectiveness: some preliminary evidence. Management Science, 29(1), 33-51.

Raschke, R.L., \& Ingraham, L.R. (2010). Business process maturity's effect on performance. In AMCIS 2010 Proceedings (p. Paper 402).

Recker, J., \& Rosemann, M. (2010). A measurement instrument for process modeling research: development, test and procedural model. Scandinavian Journal of Information Systems, 22(2), 3-30.

Ringle, C.M., Wende, S., \& Will, A. (2005). SmartPLS 2.0 (beta). www.smartpls.de.

Rohloff, M. (2009). Case study and maturity model for business process management implementation. In International conference on $B P M$ (pp. 128-142). Berlin-Heidelberg: Springer.

Rooijmans, J., Aerts, H., \& Genuchten, M.V. (1996). Software quality in consumer electronics products. IEEE Software, 13 (1), 55-64.

Scott, B. (1971). Stages of Corporate Development. Tech. rep., Working Paper. Harvard Business School 14-371-294; BP993.

Sethi, R., \& Iqbal, Z. (2008). Stage-gate controls. Learning Failure, and Adverse Effect on Novel New Products, 72(1), 118-134.

Shih, T.H., \& Fan, X. (2009). Comparing response rates in e-mail and paper surveys: A meta-analysis. Educational Research Review, 4(1), 26-40.

Škrinjar, R., Bosilj-Vukšic, V., \& Indihar-Štemberger, M. (2008). The impact of business process orientation on financial and nonfinancial performance. Business Process Management Journal, 14(5), 738-754.

Software Engineering Institute (2010). CMMI for Acquisition. Tech. Rep. November, Software Engineering Institute.

Software Engineering Institute (2010). CMMI for Services. Tech. Rep. November, Software Engineering Institute.

Solingen, R.V. (2004). Measuring the ROI of software process improvement. IEEE Software, 21(3), 32-38.

Straub, D.W., Boudreau, M.-C., \& Gefen, D. (2004). Validation guidelines for is positivist research. Communications of the Association for Information Systems, 13(24), 380-427.

Trienekens, J.J.M., Kusters, R., Kriek, D., \& Siemons, P. (2008). Entropy based software processes improvement. Software Quality Journal, 17(3), 231-243. 
Urioste, M. (2004). Tomahawk cruise missile control : providing the right tools to the Warfighter. CrossTalk, 17(9), 8-10.

Van Looy, A., De Backer, M., Poels, G., \& Snoeck, M. (2013). Choosing the right business process maturity model. Information \& Management, 50(7), 466-488.

Wangenheim, C.G.V., Carlo, J.H.R., Salviano, C.F., \& Wangenheim, A.V. (2010). Systematic literature review of software process capability / maturity models. In International conference on software process improvement and capability determination.

Wendler, R. (2012). The maturity of maturity model research: a systematic mapping study. Information and Software Technology, 54(12), 1317-1339.

Wohlwend, H., \& Rosenbaum, S. (1993). Software improvements in an international company. In Proceedings of 1993 15th international conference on software engineering (pp. 212-220). Baltimore, MD: IEEE Computer Society Press.

Remco Dijkman is associate professor in Information Systems at Eindhoven University of Technology. His research interests include Business Process Management and Service Oriented Computing. Remco has published over 70 papers in scientific journals, conferences and workshops. His work appeared in Information Systems, Computers in Industry and Transactions on Software Engineering and Methodology. He has worked as a researcher in a number of national and international research projects, including the SPICE European project; and the SHOPPS, NLI, ArCo, and A-MUSE national projects. Currently, Remco is project leader of the DAIPEX Dinalog project and the GET Service European project.
Sander Vincent Lammers holds a Bachelor and Master of Science degree in Industrial Engineering from Eindhoven University of Technology and a Master in Economics from Tilburg University. He currently works at Kempen \& Co, a Dutch Merchant Bank providing financial services in asset management, securities broking and corporate finance.

Ad ("Addy") de Jong is a Professor of Marketing at Aston Business School, Aston University, Birmingham, UK. His research focuses on how sales and service employees can improve their competences for selling and serving innovative products and services. Ad de Jong has published in several academic journals in management and marketing, including: Management Science, the Journal of Marketing, the Journal of Management, the Journal of Retailing, the International Journal of Research in Marketing, the Journal of the Academy of Marketing Science the Journal of Service Research, the Journal of Management Studies, the Journal of Product Innovation Management, Decision Sciences, Marketing Letters, and the Journal of Service Research. Ad de Jong recently served as a co-editor of a special issue on Sales \& Innovation for the Journal of Product Innovation Management. He is also a member of editorial board of the Journal of Service Research. 